\title{
Progress of marine biofouling and antifouling technologies
}

\author{
CAO Shan, WANG JiaDao* , CHEN HaoSheng \& CHEN DaRong \\ State Key Laboratory of Tribology, Tsinghua University, Beijing 100084, China
}

Received April 13, 2010; accepted July 22, 2010; published online November 26, 2010

\begin{abstract}
Adhesion of marine fouling organisms on artificial surfaces such as ship hulls causes many problems, including extra energy consumption, high maintenance costs, and increased corrosion. Therefore, marine antifouling is an important issue. In this review, physical and biochemical developments in the field of marine biofouling, which involves biofilm formation and macro-organism settlement, are discussed. The major antifouling technologies based on traditional chemical methods, biological methods, and physical methods are presented. The chemical methods include self-polishing types such as tributyltin (TBT) self-polishing copolymer coatings, which despite its good performance has been banned since 2008 because of its serious environmental impact. Therefore, other methods have been encouraged. These include coatings with copper compounds and biocide boosters to replace the TBT coatings. Biological extracts of secreted metabolites and enzymes are anticipated to act as antifoulants. Physical methods such as modification of surface topography, hydrophobic properties, and charge potential have also been considered to prevent biofouling. In this review, most of the current antifouling technologies are discussed. It is proposed that the physical antifouling technologies will be the ultimate antifouling solution, because of their broad-spectrum effectiveness and zero toxicity.
\end{abstract}

biofouling, antifouling technology, biofilm, adhesion mechanism

Citation: Cao S, Wang J D, Chen H S, et al. Progress of marine biofouling and antifouling technologies. Chinese Sci Bull, 2011, 56: 598-612, doi: $10.1007 / \mathrm{s} 11434-010-4158-4$

In the marine industry, the accumulation of living organisms on artificial surfaces by adhesion, growth and reproduction is known as biofouling. Biofouling is a particular problem for underwater structures, such as pipelines, cables, fishing nets, and bridge pillars. The adverse effects of ship hull biofouling (Figure 1) include [1]: (i) Higher fuel consumption because the frictional resistance increased due to biofouling, making the hull rougher and the ship heavier. Fuel consumption increases of about $40 \%$ have been observed because of biofouling [2], and the cost of a one-way voyage from San Francisco to Yokohama has increased by about $77 \%$ due to ship's hull fouling [3]. (ii) More expensive and time consuming hull maintenance, because drydocking operations need to be more frequent and longer with marine biofouling [3]. Moreover, these cleaning processes generate a large number of toxic substances that are discharged into the ocean. (iii) Increased ship hull corrosion

*Corresponding author (email: jdwang@mail.tsinghu.edu.cn) as the protective coating surface deteriorates because of metabolic and other biological process. This makes the hull surface more susceptible to corrosion and discoloration [4].

In the marine industry, biofouling is a huge problem, and research is focused on development of an effective antifouling solution. However, the mechanism of biological adhesion needs to be determined to allow development of antifouling strategies. In this review, an introduction to current marine fouling strategies is given, and different kinds of antifouling technologies are proposed according to the adhesion mechanism.

\section{Biofouling organisms and their adhesion mechanism}

More than 4000 kinds of marine biofouling species have been reported globally, most of which live primarily in the shallower water along the coast and in harbors that provide 

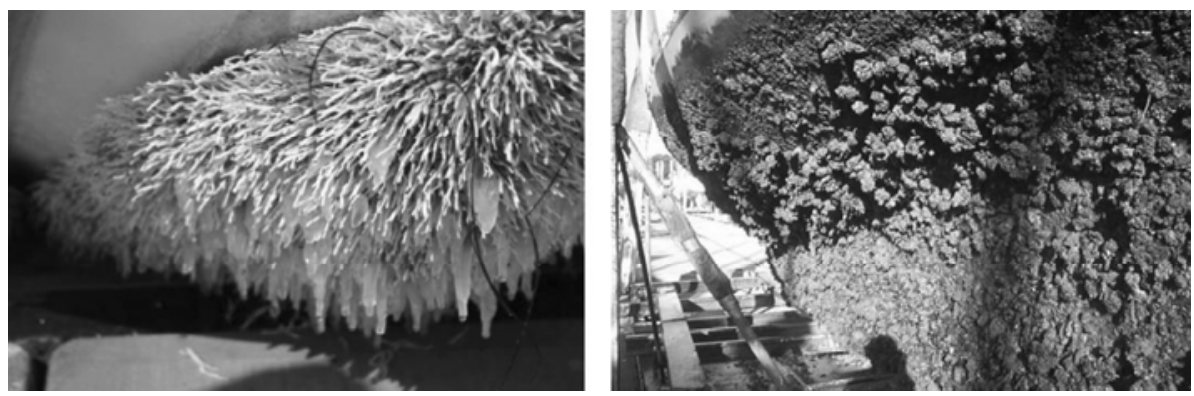

Figure 1 Heavy biofouling on the hulls of vessels.

abundant nutrients [1]. In general, marine adhesion organisms can be divided into two major categories. The first of these includes the microfouling or biofilm organisms, which are bacteria and diatoms. Biofilms are ubiquitous, as long as the surfaces are exposed to water. The other category includes macrofouling organisms such as algae and barnacles. The most important macro-fouling species are barnacles, mussels, polychaete worms, bryozoans and seaweed [5].

The biofouling process can be simplified as illustrated in Figure 2. First, through a simple physical reaction, a layer of conditioning film composed of organic materials such as protein, polysaccharide, and proteoglycan, is formed on the substrate surface. This step is short (1 min), and provides a stickier surface for microorganisms to adhere to [6].

The biofilm then develops as bacteria and microalgae adhere to the surface. Microorganism colonization involves two distinct steps: reversible adsorption, and irreversible adhesion. The former is governed mainly by physical effects such as Brownian motion, electrostatic interaction, gravity, water flow and van der Waals forces [7-10]. The latter occurs mainly through biochemical effects such as secretion of extracellular polymeric substances (EPS). During biofilm formation in the marine environment, diatoms are the most important contributors. It has been reported that microfouling alone can increase fuel consumption by up to $18 \%$, and reduce the sailing speed by at least $20 \%$ [11].

After the formation and development of the biofilm, larvae or spores of macrofoulers will attach to the surface. Two or three weeks later, these will finally evolve into a complex biological community. In marine immersion experiments, adhesion of macroorganisms usually occurs after biofilm formation $[10,13]$. However, this is not always the case $[1,14]$, for instance the larvae of some species of bryozoans [15], polychaetes [16] and some other biofoulers [17] adhere before biofilm formation.

Therefore, the process of biofouling occurs by both physical reactions and biochemical reactions (Figure 3 ). The physical reactions are governed by factors such as electrostatic interaction and water flow, and lead to formation of the conditioning biofilm and adsorption of microorganisms. The biochemical reactions include EPS secretion, movement and secondary adhesion of microorganisms, formation of the biofilm, and adhesion of macrofoulers. Whereas the physical reactions are usually reversible, the biochemical reactions are effectively irreversible. Thus, it would be easier to prevent biofouling during the physical reactions rather than the biochemical reactions. Successful inhibition of the physical reactions would constrain the later biochemical reactions.

Current research on antifouling is focused on inhibition of adhesion of diatoms and bacteria to prevent biofilm formation, though such research has also encountered numerous obstacles [1]. Some of the macrofouling organisms have been also researched in detail. The adhesion strategies of the three kinds of biofouling organisms (bacteria, microalgae,

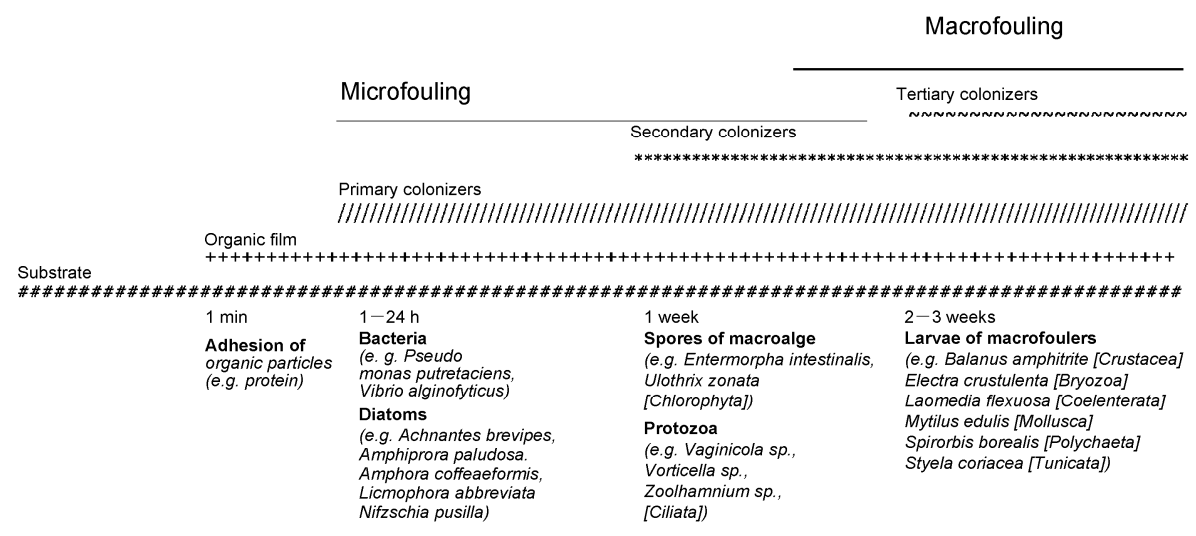

Figure 2 Temporal settlement of fouling organisms on a substrate surface [12]. 

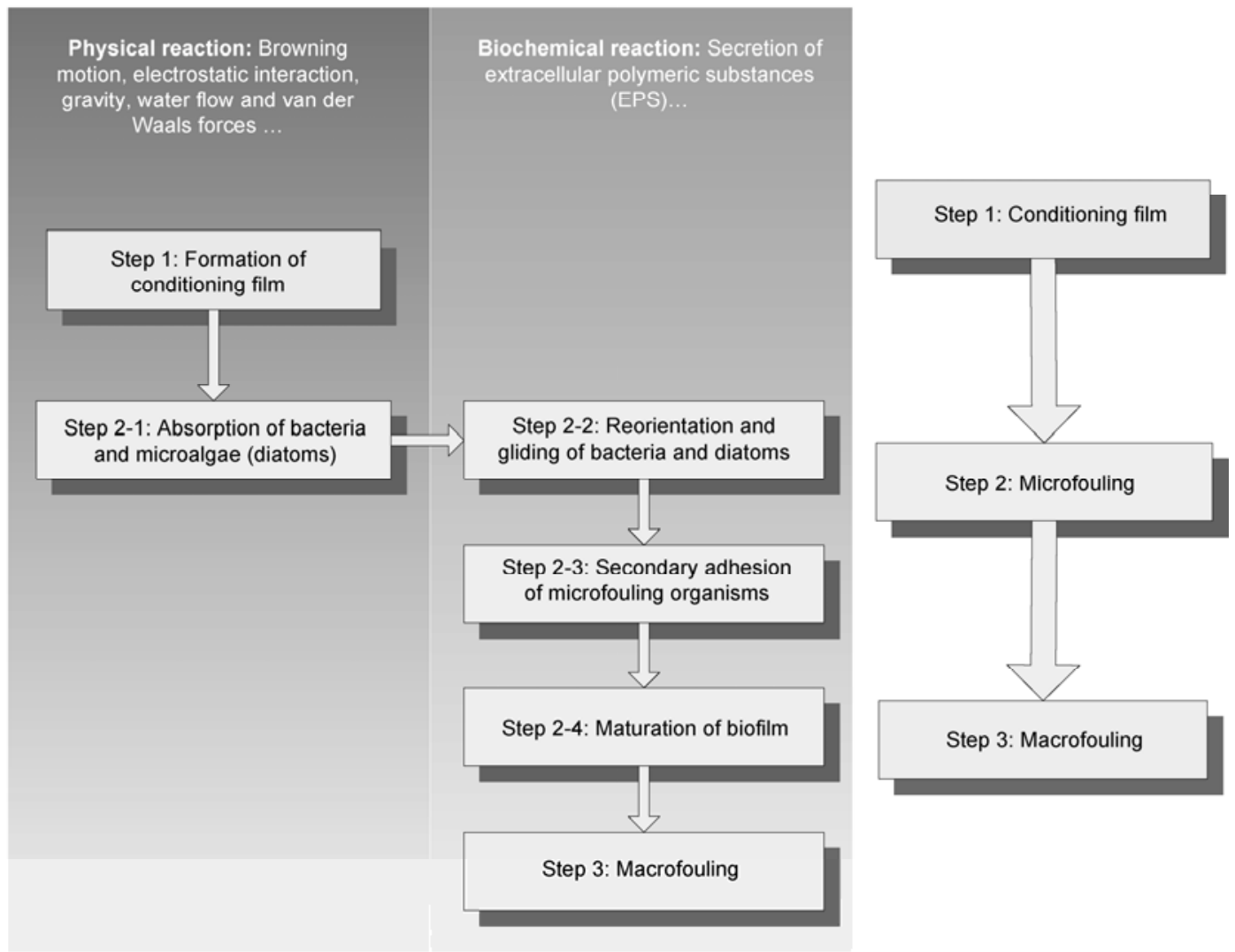

Figure 3 Biofouling process and the formation of biofilm

and macroorganisms) are discussed in sections 1.1-1.3.

\subsection{Bacterial adhesion}

Bacterial adhesion occurs as a result of the interaction of planktonic cells with the surface by physical reactions, such as electrostatic interactions [7], gravity [8] and water flow. After the initial reversible absorption, bacteria use extracellular polymers to temporarily adhere to the surface. These polymers are mainly glucose- and fructose-based polysaccharide fibrils [12]. The biofilm is formed when the bacterial communities secrete more EPS (Figure 4(a)). The biofilm is a highly organized community usually formed by a number of similar or homologous and mixed species, which has beneficial effects for the microorganisms [19,20]. After maturation of the biofilms, they disperse cells into the water to expand the species (Figure 4(b)) [21].

The premise of the phenotypical change between reversible and irreversible states is a cell density-dependent system called quorum sensing. As the name indicates, the bacteria cell is able to sense that it is part of a concentration of cells of a certain size (the quorum), by recognition of specific low-molecular-weight signal compounds secreted and accumulated by the cells in the quorum. The quorum sensing system is important for many aspects of cell survival [22].
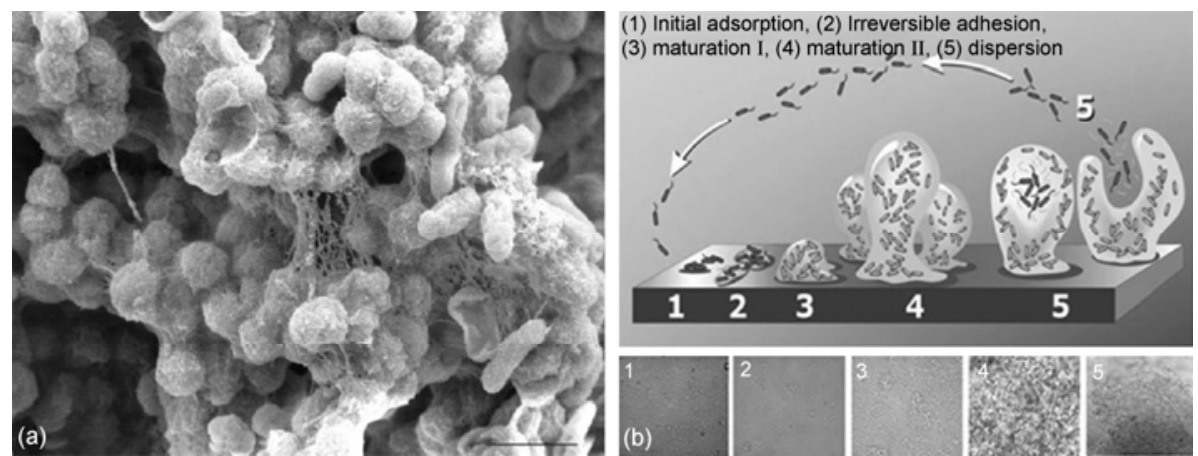

Figure 4 Biofilm formation. (a) SEM photographs of EPS produced by Salmonella (scale bar $=2 \mu \mathrm{m}$ ) [18]; (b) biofilm formation in five steps: initial adsorption, irreversible adhesion, maturation I, maturation II, and dispersion [21]. 
Generally speaking, the mass of cells in biofilms accounts for only $2 \%-5 \%$ of the total weight with the remainder contributed by the EPS matrix, which includes a variety of extracellular carbohydrates, proteins, nucleic acid, glycoprotein, phospholipids and other surfactants. The ratio of these various extracellular compounds excreted by various species is quite different [23,24], and even the same species secret different EPS compounds under different circumstances [18]. Among those compounds, the polysaccharides are highly heterogeneous, containing different sorts of monosaccharide units and inorganic materials [25]. The secreted proteins, many of which are polymer-degrading enzymes, also have heterogeneous compositions, although there is evidence that different proteins share some common substances or features. For instance, the surface protein Bap [26], amyloid fibril and $\beta-1,6-\mathrm{N}$-acetyl glucosamine [27-29], and the sequence GGDEF/EAL [18] are found in different proteins.

These factors illustrate the lack of many common features among different biofilms, which makes broad-spectrum antifouling a difficult target.

\subsection{Microalgae adhesion}

The major eukaryotic marine fouling microorganisms are diatoms, fungi, and protozoan, and the dominant organisms are diatoms $[12,13]$.

Diatom adhesion is a more complicated process than that for bacteria. Because most of the diatoms lack flagella, they cannot actively approach a given surface, but passively land on the substratum. For example, benthic diatoms approach surfaces through the effects of either gravity [30] or water currents [31-33]. Plankton diatoms, which have almost the same specific gravity as seawater, land on surfaces mainly via turbulence [34]. Moreover, electrostatic interactions such as Coulomb attraction and electrostatic contact potential are also involved [35]. During contact between diatoms and a surface, van der Waals forces may also operate, and this has been observed in other adhesive situations [36].

After the diatoms land on the surface, they actively form the initial reversible attachment called primary adhesion through secretion of EPS. The diatoms then reorient themselves and move along the surface into better positions based on their preferences, this process is called diatom gliding. Many scientists have focused on diatom gliding in the belief that this would help to understand the adhesion mechanism. However, Holland et al. [37] found no relation between adhesion and locomotion of diatoms. It is generally acknowledged that diatom gliding is the result of an actin-myosin motility system meditated by extracellular proteoglycans. Actin was first identified near the position of the raphes (Figure 5(a), (b)), and its involvement in cell motility has been the focus of many studies [38,39]. Later experiments proved that both anti-actin drugs and antibodies to cell surface proteoglycans inhibit diatom gliding [39,40]. However, the underlying mechanism generating force for diatom gliding is currently poorly understood. Some mechanical models for locomotion have been calculated in earlier studies $[41,42]$, and some reasonable cell locomotion mechanisms have been proposed (Figure 5(c)) [43]. After diatom gliding, if the diatoms continue their life cycles in that position, they will form irreversible secondary adhesion by secreting a large amount of EPS [44-46]. Individual diatoms commonly generate EPS like stalks in this period $[45,47,48]$.

EPS of diatoms is composed of carboxylated or sulfated acidic polysaccharides, which are involved in the primary adhesion, and proteoglycans, which are involved in diatom gliding and cross-linking stabilization of the biofilm matrix [40]. As with bacteria, EPS produced by different types of diatoms are diverse $[49,50]$, and include various protein fractions and complex anionic polysaccharides with heterogeneous combinations of monosaccharide [45]. In addition, at least two types of mucilage can be detected for the same species of diatom [51,52]. However, some common features have been detected among different diatoms, such as
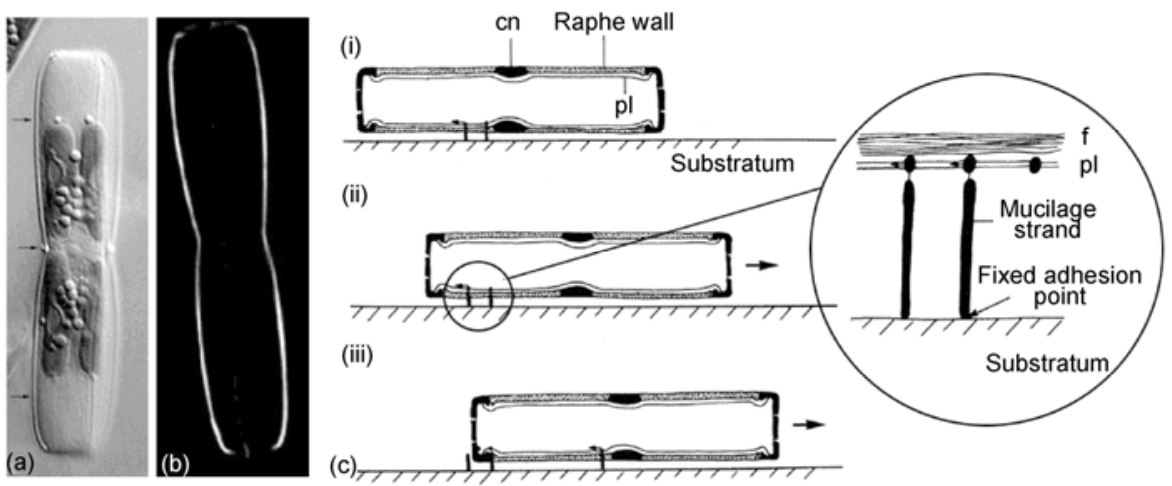

Figure 5 Actins in diatoms and proposed diatom locomotion mechanism. (a) Cell of Craspedostauros australis in girdle view [39]; (b) fluorescein (FITC) phalloidin stained cell of C. australis in also girdle view, which indicates F-actin along the raphe [39]; (c) proposed cell movement mechanism [43] involving: (i) secretion of mucilage strands at the central pore, and their attachment to membrane components and substratum; (ii) relative backward movement of the membrane components, which leads to forward displacement of the framework itself and of the cell as a whole; (iii) breaking of the mucilage strands, which forms a short-lived trail. 
general structural components by time of flight-secondary ion mass spectrometry (TOM-SIMS) [53], and modular proteins and their supramolecular assemblies of adhesive nanofibers (ANFs) [54]. These common traits could be targeted in a method to combat diatom adhesion.

As mentioned above, we have some primary understanding of the mechanisms of diatom gliding and adhesion, though the hypotheses still lack theoretical support. For example, the mechanism by which the secreted mucilage and actin generate force is unknown. Aspects of diatom adhesion are even more uncertain, such as how it is initiated or inhibited, and cannot be explained by the established theory of mucilage secretion.

\subsection{Macro-organism adhesion}

The most problematic biofouling effects arise because of colonization of macroorganisms such as spores of macro algae, barnacle larvae, bryozoans, molluscs, polychaete, tunicates, and coelenterates [12].

A common trait of macroorganism settlement is biofilm cueing. As early as 1963 , it was shown that the increased diatom concentrations could induce maturation of barnacle larvae [55]. However, subsequent experiments have shown that biofilms do not facilitate settlement of all macroorganisms. This has been demonstrated in a variety of marine organisms such as barnacles, oysters, and Ulva [25] fed by bacteria [56] and diatoms [57]. Because of competition for nutrients and light, it is believed that microorganisms produce metabolites to repel specific macroorganisms [58].

Another common characteristic of macroorganism settlement is physiochemical cueing. Some experiments have shown that invertebrate larvae seem to be able to select suitable substrates, and their choice is determined by surface topography, water streaming conditions and chemical properties [25]. Moreover, it is generally accepted that larval settlement and metamorphosis are influenced by chemical cues originating from conspecific adults, prey organisms, and substrates [59].

Though the settlement of macroorganisms follows the above common guiding cues, adhesion mechanisms are quite different in specific organisms. Barnacles and Ulva have been investigated as representatives of invertebrate and macroalgae groups, respectively. The settlement mechanism of barnacles has been studied in great detail, and results indicate that the cyprid antennule consists of four segments that are responsible for crawling, attachment and sensory functions [60]. When an appropriate surface is found, the cyprid will adhere by secretion of granulated cement containing high concentrations of proteins. This cement embeds the antennular attachment organs and hardens because of protein polymerization. After stable settlement, cyprids metamorphose into juvenile barnacles, and finally become adults [61].

Ulva spores are another well-studied macroorganism, and are extremely important in biofouling because of their abundance in seawater and adaptability to different environments [12]. The motile spores have four flagella and no polysaccharide-rich cell wall. Typically, Ulva spores adhere to the surfaces by secreting glycoprotein, and then retract the flagella and form a cell wall [62-64]. However, in some special conditions spores will exhibit abnormal pseudosettlement [65]. Freshly released glycoprotein from Ulva spores has strong adhesion strength, and the spores cannot be removed under the speed of most vessels [66].

Protein adhesives from algae, mussels, and polychaetes have several features in common, including high contents of lysine, glycine and serine, and extensive polypeptide repeats with abundant dihydroxyphenylalanine (DOPA) side-chains, which will displace water molecules to facilitate strong adhesion $[25,67]$. However, they are quite different from the barnacle adhesives $[68,69]$.

\section{Antifouling methods}

The severity of biofouling depends on a large number of parameters, including temperature, salinity, light, geography, depth, and voyage speed $[1,70]$. For example, biofouling is generally more serious in areas with high water temperature because this is the principal condition determining breeding periods and rates of growth of biofouling organisms [71]. Unfortunately, these important factors cannot be modified to a large extent. Therefore, to effectively prevent biofouling, a variety of coatings have been investigated to chemically inhibit the fouling organisms. From another point of view, during the development of microtechnology, the influence of microscale physical factors on biofouling has been researched and some new antifouling technologies have arisen that involve changing physical factors. In addition, microorganisms can secrete metabolites that inhibit the attachment of some macroorganisms [72], and concentrated extracts of these metabolites could also be effective antifouling agents.

In summary, antifouling methods can generally be divided into three categories: chemical, physical, and biological methods.

\subsection{Traditional chemical methods}

Biofouling has been recognized as problematic for more than 2000 years [73], and many kinds of antifouling methods have been investigated over this time [1]. Since the late 20th century, organic tin and its derivatives have been widely used as antifouling coatings because of their activity against a wide range of fouling species. Organotin compounds that have been used as antifoulants include tributyltin oxide (TBTO), and tributyltin fluoride. Those antifouling organotin compounds are powerful fungicides, and will completely inhibit the growth of most fouling 
organisms at a very low concentration [74]. The paints containing these compounds can be classified as those with insoluble and soluble matrices, according to the chemical characteristics of the binder and their water solubility.

Insoluble matrix antifouling paints have a polymer matrix (such as vinyl and epoxy) that will not erode in water [1]. When the coating is immersed in seawater, the soluble toxic materials dissolve, which leaves a multiporous structure known as the leached layer. Seawater then penetrates deeper into the film and more poisonous materials dissolves in the water. The advantage of this kind of paint is that the structures are mechanically strong and stable to oxidation and photodegradation. Thus the coatings can be made very thick to increase the content of toxic materials. However, at some stage the leached layer will be so thick that water cannot penetrate any deeper, and the rate of release will fall under the minimum value required for antifouling (Figure 6(a)). Therefore, the lifespan of insoluble matrix antifouling paints is as short as 12-18 months [75].

To lengthen the lifespan of antifouling coatings, soluble matrix antifouling coatings were developed. As implied by the name, both the toxic materials and matrix, which contains a great amount of resin, can dissolve in seawater. In this case, the leached layer can be much thinner and toxic materials deeper in the film can be easily exposed to water, which lengthens the lifespan of the antifouling coating (Figure 6(b)) [1]. The release rate will exponentially increase as the sailing speed increases. However, during the static conditions that favor settlement of fouling organisms the pores of this coating can become blocked by insoluble salts, which greatly reduces the release of biocides [76]. In addition, because of the resin's brittleness and instability to oxidation, its mechanical properties are inferior to those of insoluble matrix coatings.

\subsection{Modern chemical antifouling methods}

(i) Tributyltin self-polishing copolymer coatings. As noted in section 2.1, both insoluble and soluble matrix antifouling coatings have their deficiencies. Consequently, alternative coatings have been investigated. In 1974, Milne and Hails patented the first TBT self-polishing copolymer (TBT-SPC) technology, which provided an excellent antifouling effect that revolutionized the entire shipping industry [1].

TBT-SPC paints are based on acrylic polymer (usually methyl methacrylate) with TBT groups bound to the polymer backbone by an ester. When immersed in water, the soluble pigment particles (such as $\mathrm{ZnO}$ ) begin to dissolve [77]. The polymer of TBT methacrylate and methyl methacrylate is hydrophobic, which prevents water from infiltrating the paint film. Therefore, water can only fill the pores generated by the dissolution of soluble pigment particles. Moreover, the carboxyl-TBT linkage is easily hydrolyzed in slightly alkaline environments such as in seawater (pH 7.5-8.5). This results in cleavage of the TBT portion from the copolymer, and releases the biocides into the water [74]. Once many TBT portions have been cleaved, the partially reacted brittle polymer backbone can be easily washed off by the moving seawater, which exposes a fresh coating surface (Figure 7(a),(b)) [74,78]. The hydrolysis process provides a low hull roughness (about $100 \mu \mathrm{m}$ ), so as not to increase the resistance of the ship's hull [1].

One of the major advantages of an antifouling coating such as this is that manipulating the polymer chemistry can
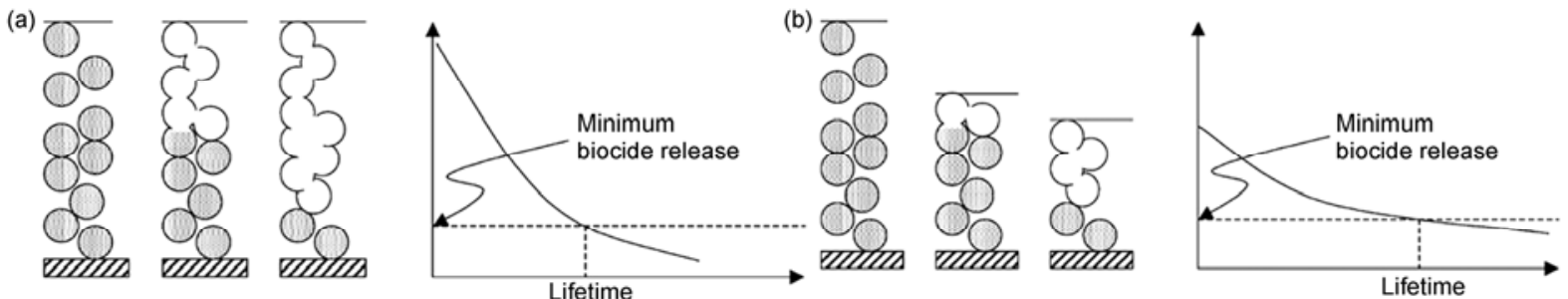

Figure 6 Method of release and biocide release rates of (a) insoluble matrix paints and (b) soluble matrix paints [1].

(a)

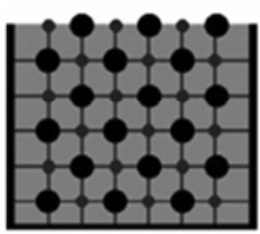

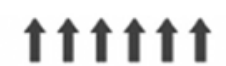

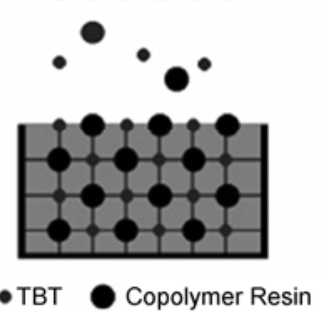

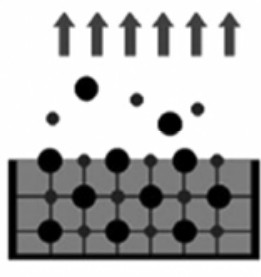

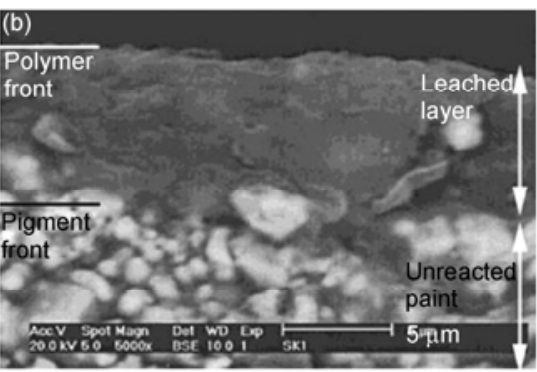

Figure 7 TBT-SPC system and cross-sectional SEM image. (a) Self-polishing TBT copolymer system [74]; (b) SEM image showing cross-section of TBT-SPC (magnification 5000×) [78]. 
control the polishing rate. Therefore, it is possible to balance high effectiveness and a long lifespan, and the coatings can be customized for ships operating under different conditions, such as duration of their idle periods and sailing speed [1]. It has been shown that release rate of TBT in seawater is almost constant with sailing speed, and thus high antifouling performance can be obtained even if the ship is not moving. In addition, the maintenance is convenient and low cost. Moreover, TBT-SPC paints have high mechanical strength, high stability to oxidation, and short drying times [74]. The unavoidable formation of biofilm does not largely affect the net biocide leaching and binder reaction rates [79]. Therefore, in general, the TBT-SPC antifouling coating was widely applied in the shipping industry before it was banned.

(ii) Tin-free SPC technology. As discussed edrlier, TBT-SPC coatings have many advantages as antifouling coatings. However, the damaging effect of TBT on nontarget organisms cannot be ignored. Consequently, TBT has been restricted as of the International Maritime Organization (IMO) conference in 1998, and these coatings have been banned from 1 January, 2008 [80]. Therefore, TBTfree systems have been commercially introduced.

Generally speaking, the tin-free antifouling coatings can be divided into two categories: controlled depletion systems (CDPs), and tin-free self-polishing copolymers (tin-free SPCs). The former coatings upgrade the traditional soluble matrix technology by incorporating modern reinforcing resins with the same antifouling mechanism as the conventional resin matrix paints. The latter coatings function in a similar manner to TBT-SPC but do not contain tin. Currently, these two types of paints are produced by many companies, including Ameron, Chugoku MP, and Hempel's MP [1]. The differences between CDPs and tin-free SPCs are illustrated in Table 1, and from these parameters we can see the performance of tin-free SPCs is better than the CDPs.

Tin-free SPCs react in a similar to organic tin SPCs, but their matrix material is mostly acrylic copolymer and non-tin metals such as copper, zinc, and silicon. For example, the Exion series from Kansai Paint [1] uses insoluble $\mathrm{Zn}$ acrylate, which hydrolyzes to soluble acidic polymer. The following reaction is assumed:

$$
\text { Polymer-COO-Zn(solid) }-\mathrm{X}+\mathrm{Na}^{+} \rightarrow
$$

$$
\text { Polymer-COO- } \mathrm{Na}^{+}(\text {solid })+\mathrm{X}^{-}+\mathrm{Zn}^{2+} \text {. }
$$

The $\mathrm{Zn}^{2+}$ is discharged into water for antifouling, and the soluble acidic polymers can be washed from the surface. Beside zinc, the majority of tin-free antifouling paints currently available contain copper, and some contain silver [81]. Currently, the major copper compounds used for antifouling include metallic copper, cuprous thiocyanate, and cuprous oxide $[82,83]$. Copper ions as $\mathrm{Cu}^{2+}$ have a major role in antifouling [1].

Compared with the broad-spectrum TBT antifouling coatings, copper-containing coatings can only target specific fouling organisms. Biological indicators differ widely with respect to copper sensitivity, and a general decreasing order of sensitivity would be: microorganisms $>$ invertebrates $>$ fish $>$ bivalves $>$ macroalgae [84]. Therefore, some booster biocides that are highly toxic to macroalgae, barnacles, and bryozoans are added to improve the antifouling proprieties. These biocides include Irgarol 1051 and Diuron $[83,85]$, copper pyrithione and isothiazolone $[1,86]$.

Undoubtedly, there is concern about the influence of copper containing coatings and booster biocides on the marine environment [85]. However, a number of scholars have highlighted that the boosters are biodegradable materials with short half-lives. Unfortunately, the heavy metals do bioaccumulate in the internal organs of marine life [87]. Generally speaking, there is no simple and nontoxic solution for the biofouling problem [88]. However, copper containing coatings are considered as a transition between toxic and non-toxic coatings.

(iii) Non-toxic antifouling technology. Although in the short term, no alternative antifouling technology seems capable of replacing biocide-based coatings, there are some non-toxic technologies that have been developed.

For instance, non-stick fouling-release compounds (such as silicone coatings) have been trialed for antifouling through release of macrofouling organisms when hydrodynamic conditions are sufficiently robust $[1,37]$. In this case, it appears that fluoropolymers and silicones possess the necessary properties for antifouling by release [1]. Some low surface energy coatings have also been prepared with modified acrylic resin and nano- $\mathrm{SiO}_{2}$ [89]. However, accumulated fouling organisms are not as easily released as anticipated [37,90,91]. In addition, this method has many deficiencies, such as high cost, poor mechanical properties,

Table 1 Contrast of performance of CDPs and tin-free SPCs

\begin{tabular}{lll}
\hline & CDPs & Tin-free SPCs \\
\hline Self-polishing & Poor & Smooth paint surface during sailing \\
Leached layer & Thick & Thin and stable \\
Biocide release & Hard to control, not constant & Continuous and constant at the same velocity and sea water conditions \\
Idle periods & Little activity & High activity \\
Lifetime duration & Short, up to 3 years & Long, 5 years \\
Maintenance & High cost, sealer coating needed & Low cost, re-coating directly \\
\hline
\end{tabular}


and the difficulty of recoating. Therefore the antifouling performance is limited, which leads to increased interest in other methods. Generally speaking, non-toxic antifouling technology research can explore either biological or physical methods.

Biological methods involve using a variety of enzymes or metabolites secreted by cells as substitutes for traditional biocides [23]. Because these organic secretions are biodegradable, they should be environmentally friendly [25].

Physical methods include electrolysis, radiation, and other physical methods to reduce biofouling. They can also utilize modification of surface physical properties, such as topography or charge potential, to minimize adhesion strength [1].

\section{Biological methods}

As mentioned in earlier, some organisms can secrete enzymes or metabolites to inhibit the growth of their competitors. These secretions have low-toxicity and are biodegradable, and have received much attention in recent years. Researchers have attempted to extract high concentrations of these secretions to use for biological antifouling. As early as 1999, it was reported that the active substances secreted by blue algae could inhibit the growth of diatoms [92]. Functional antifouling components have also been discovered in other organisms such as fungi [93], sponge [94] and some other bacteria $[95,96]$.

The application of enzymes as antifouling agents has been successfully investigated recently. Many types of enzymes, such as oxidoreductases, transferases, hydrolase, lyase, isomerase, and ligase, have been reported to have antifouling capabilities [25,58,97-106]. From the perspective of enzymatic antifouling technology, biofouling problems are caused by the formation and reproduction of biofilms, and the adhesion of spores and larvae of macroorganisms. Therefore, the functions of enzymes for antifouling applications can be divided into the following four categories: degradation of adhesives used for settlement, disruption of the biofilm matrix, generation of deterrents/biocides, and interference with intercellular communication.

\subsection{Enzymes that degrade adhesives used for settlement}

In the case of macrofouling, proteins and proteoglycans have a dominant role in the adhesion process. As is widely known, proteases can hydrolyze peptide bonds at different sites, and this kind of enzyme can be used to degrade mucilage based on peptide and hence prevent biofouling. For example, the attachment of Ulva spores, barnacle cyprids and bryozoans can be effectively inhibited by serine protease $[58,98]$. It has been confirmed that this inhibition is caused by reduction of adhesive effectiveness rather than any toxic or deterrent effect [105].
In the case of microfouling, the process is more complicated $[98,103]$, because polysaccharide-based adhesives are as important as proteins during secondary adhesion. Generally, polysaccharide degradation is executed by glycosylase. However, to degrade polysaccharides is difficult because the process is quite complex [106] and glycosylase can target only a limited range of linkages. Consequently, it would be difficult to choose an appropriate glycosylase for broadspectrum antifouling [103].

\subsection{Enzymes that disrupt the biofilm matrix}

Because of the variety of EPS, biofilms are very complex and the disintegration of their polymeric networks would require very broad combinations of both hydrolases and lyases [25]. In addition, because biofilms are very adaptable to external conditions, the degradation of the crucial component will induce the generation of alternative components that will replace the original and establish a new network to proliferate the organisms [107]. This means that the biofilm will not disintegrate. Tests have shown that though alginase could detach a thin biofilm [108], it had no effect on an identical biofilm that was already fully established [107].

In summary, because of the complexity and adaptability of the biofilm, the antifouling method of disrupting the biofilm matrix may not be suitable and effective.

\subsection{Enzymes that generate deterrents and biocides}

In recent years, antifouling research has focused on the extraction of metabolites secreted by different marine animals or plants that have strong antifouling ability. Such antifouling compounds should be regarded as deterrents rather than toxins [23,25].

Some of the enzymes that have such effect include glucose oxidase, hexose oxidase, and haloperoxidase [25,99]. For instance, glucose and hexose oxidase is used to generate hydrogen peroxide to induce oxidative damage in living cells [109], and haloperoxidase catalyses the formation of hypohalogenic acids usually used in water treatment systems as disinfecting agents [25]. In addition, hydrogen peroxide will decompose into water and oxygen, and the rate of this process is quite high in seawater [110]. Hypohalogenic acids have similar characteristics, and could also be investigated in future as nontoxic and biodegradable antifouling substances [99].

\subsection{Enzymes that interfere with intercellular commu- nication}

As discussed in section 1.1, quorum sensing has an important role in the formation of biofilms. Studies have shown that $N$-acyl homoserine lactones (AHL) are required for quorum sensing by some Gram-negative bacteria [22]. Therefore, elimination of AHL may thus prevent the 
development of bacterial fouling [25]. AHL acylase degrades AHL, and as the concentration of this enzyme increases, biofilm formation is inhibited and the settlement of Ulva spores and polychaete larvae is affected [110,111]. Consequently, AHL acylases can also inhibit the settlement of macroorganisms to some extent.

\subsection{Challenges for enzymatic antifouling methods}

The seawater temperature ranges from $-2^{\circ} \mathrm{C}$ to $30^{\circ} \mathrm{C}$, which can largely affect enzyme catalytic activity and stability. In addition, each enzyme will itself decompose if the temperature is too high, and then the lifespan of the enzymatic antifouling coating will also decrease. Therefore, balancing of the effectiveness and lifespan will be a major challenge. Furthermore, the design of an appropriate coating matrix to contain the enzymes will be another crucial step for successful application [112]. In addition, the distribution of enzyme and its amount should also be analyzed in detail, because soluble enzymes will soon form a thick leaching layer.

\section{Physical antifouling methods}

\subsection{Antifouling by electrolysis and radiation}

Many methods for physically preventing biofouling have been investigated. Among them, the most common method is to produce hypochlorous acid $(\mathrm{HClO})$, ozone bubbles, hydrogen peroxide or bromine through electrolysis of seawater $[1,113,114]$. Because of their strong oxidizing ability, $\mathrm{HClO}$ and other compounds will spread all over the ship's hull and eliminate areas of fouling organisms. However, some of these systems are not highly efficient because of a large voltage drop across the surface, and they will intensify the corrosion problems of steel. Consequently, titaniumsupported anodic coating has been suggested because of its advantages such as having low decomposition tension, higher current efficiency, lower energy consumption [115], although the development of this has been limited. Antifouling could also be achieved by microcosmic electrochemical methods, which are based on direct electron transfer between an electrode and the microbial cells. This causes electrochemical oxidation of the intercellular substances, but is expensive and the efficiency has not been established [25].

The antifouling abilities of vibration methods, such as acoustic technology, have also been confirmed [116]. Нydroids, barnacles and mussels can be inhibited to some extent by either external vibration sources or piezoelectric coatings [117]. However, the huge power consumption of these methods is difficult to overcome.

Finally, other studies have evaluated magnetic fields, ultraviolet radiation and radioactive coatings [1], but these methods are not practical in application. An additional potential method involves the use of substrates with different colors, which affect the attachment and growth of spores and worms [118,119].

\subsection{Antifouling by modification of surface topography and hydrophobic properties}

As stated in section 1.1, biofilm is mainly formed by microorganisms, including bacteria and microalgae, which are approximately $1-100 \mu \mathrm{m}$ in size. At this scale it is possible to precisely modify the surface microstructure. Therefore, in recent years, varying surface characteristics, including surface roughness, topography, hydrophobic behavior, and lubricity, have been investigated for antifouling application [120]. To simplify the models used in these studies most researchers regard diatoms or bacteria as representative adhesion organisms.

Because of material properties, surface wettability has a large impact on the adhesion of biofouling organisms. Study has shown that fouling diatoms [37] adhere more strongly to a hydrophobic polydimethylsiloxane (PDMSE) surface than to glass. For other fouling organisms such as bacteria and Ulva spores, if the surface contact angle is greater than the adhesion is stronger [121-124]. However, the strength of attachment of Ulva spores is greater to hydrophilic than hydrophobic surfaces [66,125]. Moreover, hydrophilic surfaces are thought to be capable of antifouling. For example, antifouling behaviors are exhibited when adding metal nanoparticles such as $\mathrm{TiO}_{2}$, because the photocatalytic activities introduced by solar ultraviolet will make the surface more hydrophilic so that the formed biofilm is washed more easily [126]. However, some species studied have exhibited opposite adhesion behavior on the same sets of surfaces, highlighting the importance of differences in cell-surface interactions $[32,66]$. Therefore, the differences in settlement and adhesion behavior have inspired the development of a surface that presents both hydrophilic and hydrophobic domains to settling (attaching) cells and organisms. Different patterns of such surfaces have also been evaluated [127, 128].

Surface topography also affects the adhesion of fouling organisms. It has been shown that rougher surfaces increase adhesion of Pseudomonas [129]. Furthermore, Scardino et al. proposed the attachment point theory (Figure 8), which indicates that more attachment points during adhesion results in stronger more prolific adhesion [130,131]. This theory is consistent with the settlement of barnacle cyprids [132].

The effects of feature size, geometry and roughness on the settlement of zoospores of Ulva were evaluated using engineered micro topographies in PDMSE. The results identified an engineered roughness index (ERI) that can influence antifouling [133]. ERI could be calculated as: $\mathrm{ERI}=\left(r^{*} d_{\mathrm{f}}\right) / f_{\mathrm{D}}$, based on Wenzel's roughness factor $(r)$, the depressed surface fraction $\left(f_{\mathrm{D}}\right)$, and the degree of freedom of spore movement $\left(d_{\mathrm{f}}\right)$. Different surface topographies (Figure 
(a)
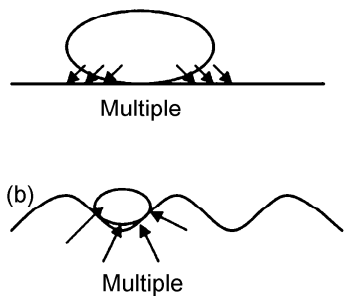

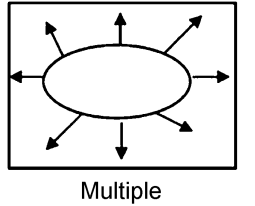

(c)

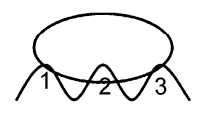

(d)

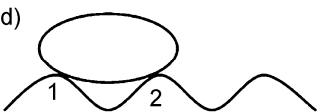

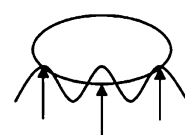

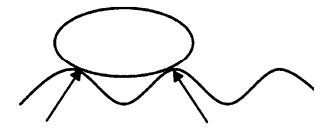

Figure 8 Attachment point theory experiments, which illustrate that the adhesion strength is highest in (a) and (b) (multiple attachment points) and lowest in (d) (least attachment points) [130].

9(a)) have different ERIs, and that with the largest ERI (Sharklet $\mathrm{AF}^{\mathrm{TM}}$ ) will perform most effectively as an antifoulant. It was proposed that the responses were governed by the same underlying thermodynamic principles as wettability [134]. The Sharklet AF surface was also tested with other organisms such as Staphylococcus aureus (Figures 9(b) and (c)) and appeared to have effective antifouling performance [135]. The effectiveness of designed nanoforce gradients for antifouling applications was tested with Ulva, and the results showed the surfaces with nanoforce gradients ranging from $125-374 \mathrm{nN}$ all greatly reduced spore settlement [136].

Multivariate methods were used to identify relationships between bacterial attachment, water transport, and the surface properties of modified polysulfone (MPS) membranes, which showed that the interrelations were quite complicated [137]. In summary, the research into modification of surface topography to achieve antifouling is still at the experimental stage. The identification of effective antifouling topographies typically occurs through trial-and-error rather than predictive models. Although some empirical principles such as attachment point theory and the ERI index have been proposed, these theories are not sufficient to explain the real situation. Therefore, these formulas are not expected to guide the development of antifouling methods.

\subsection{Antifouling by changing the zeta potential}

As mentioned in section 1, microbial adhesion is compli- cated and influenced by many physical reactions, while electrostatic interactions are expected to have a major role [138]. Therefore, potentials of the surfaces or microfouling organisms have been measured to determine the relationship between them.

It is well known that bacterial cell surfaces possess net negative electrostatic charge because of ionized phosphoryl and carboxylate substituents on outer cell envelope macromolecules that are exposed to the extracellular environment. The influence of peripheral electronegativity can be assessed based on the measurement of zeta potential (Figure $10(a)$ ), which is most often determined by estimating the electrophoretic mobility of cells in an electric field [139]. ZPs of many microorganisms have been measured in different physiological states [140], such as for Chlorella $(\mathrm{ZP}=-17.4$ to $-19.8 \mathrm{mV}$, independent of $\mathrm{pH}$ from $4-10)$, diatom Nitzschia ( $\mathrm{ZP}=-28 \mathrm{mV}$, stationary phase) [141], and Pseudomonas sp. $(\mathrm{ZP}=-46.9 \mathrm{mV})$ [140]. Microorganisms are negatively charged over a large $\mathrm{pH}$ range (Figure 10(a)), and in natural sea water $(\mathrm{pH} 7-8)$ will carry a negative charge [142]. As a result, electrostatic interaction between cells and metal cations promotes the adhesion process.

In some other industries, varying the $\mathrm{pH}$ of the suspension and hence shifting the surface charges of the bacterial cells has been used as an effective method to reduce biofouling [143]. However, it is impractical in the case of marine fouling. Consequently, attempts have been made to modify the charge potential of the surfaces to inhibit the cells from attaching to them to some extent. Fouling by
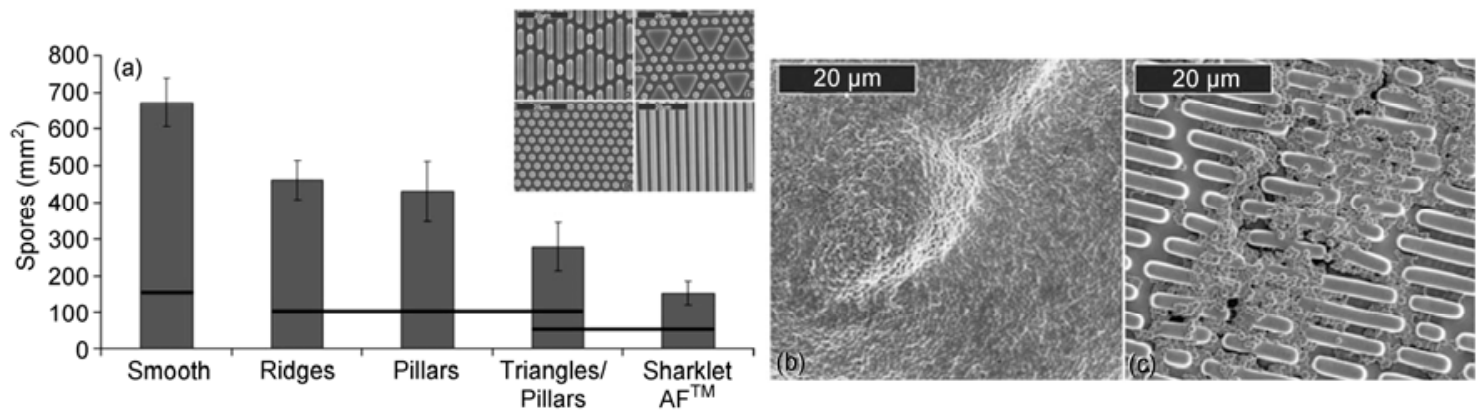

Figure 9 Spore attachment on surfaces with different topographies. (a) SEM images of engineered topographies on PDMSE surface and corresponding spore settlement data [133]. Uniform surface of circular pillars (ERI=5.0) or wide ridges (ERI=6.1) reduced settlement by more than 30\%. A multi-featured topography consisting of pillars and equilateral triangles (ERI=8.7) reduced spore settlement by 58\%. The largest reduction 77\%, was obtained with the Sharklet AF topography (ERI=9.5). SEM images of $S$. aureus on smooth PDMSE (b) and Sharklet AF surface (c) after $21 \mathrm{~d}$ [136]. 
(a)

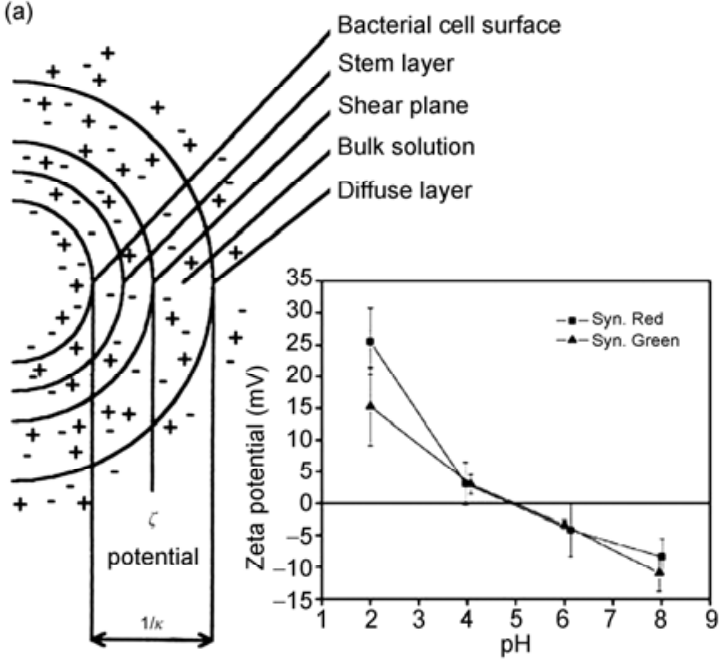

(b)

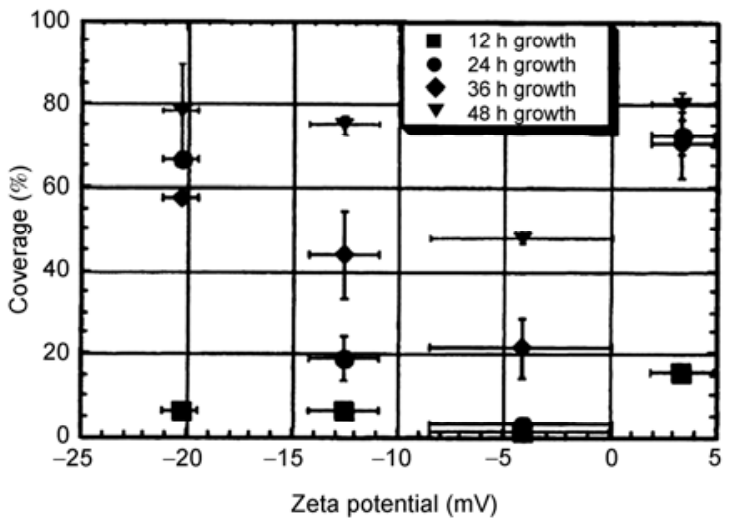

Figure 10 Zeta potential with diatom cells. (a) Cross-section representation depicting the various solvent layers surrounding a bacterial cell [139], and zeta potentials of two picocyanobacterial strains as a function of $\mathrm{pH}$ [142]; (b) fouling coverage of $P$. aeruginosa vs. zeta potential of nylon membranes after various periods of time [129].

Pseudomonas aeruginosa was minimal when the surface charge was minimized, and increased with increasing charge (positive or negative) (Figure 10(b)) [129]. Ulva spores were demonstrated to have a reduced tendency to settle on negatively charged surfaces of polytetrafluoroethylene (PTFE) [64]. Many other phenomena observed during microorganism settlement on self-assembled monolayers $[121,144]$ can be partly explained by electrostatic interactions $[145,146]$. Discharge treatment can be used to create carboxylic acid groups on polymer surfaces [147], which can also be discussed in terms of the repulsive electrostatic interactions [148].

\subsection{Challenges for physical antifouling methods}

In summary, in most cases there are no convincible theories to explain different antifouling performance by modification of surface zeta potential, topography, and wettability. Consequently, many experiments investigating various parameters are insufficient for solving biofouling problems. Detailed information on the biological adhesion mechanism is required as the biofouling process is a complex biochemical problem rather than a pure physical problem.

\section{Conclusions}

In general, biofouling on marine structures is characterized by two critical events: the formation of biofilms, which includes reversible physical adsorption, irreversible secondary adhesion, and then proliferation of the microorganisms; and the settlement and growth of spores or larvae of macroorganisms. In most cases, it is easier for macroorganisms to settle on specific biofilms through cueing than on the surface without biofilms. Thus, it is important to research ways to prevent biofilm formation. Because diatoms are the dominant organisms in biofilms, they have been widely evaluated in a variety of experiments as a representative of microorganisms.

Many kinds of antifouling technologies have been investigated to counteract the marine foulers. For instance, TBT-SPC is one of the most effective antifouling methods. However, biocide-based antifouling coatings are environmentally unsuitable, and research on non-toxic coatings is of importance. This research generally focuses on physical methods, including electrolysis and radiation, modification of surface structures and wettability, or change in the charge potential of surfaces. The alternative is biological methods, including using enzymes or metabolites secreted by cells to replace toxic biocides.

In the case of biological methods, the current situation shows that enzymes degrading adhesives (proteases and glycosylases) and enzymes interfering with intercellular communication (acylase) can effectively prevent biofouling. The former approach is mainly targeted at macroorganisms and the latter at microorganisms, and some kind of combination of both enzymes will possibly produce a better result. Further documentation of trials on marine crafts should be obtained, and the various enzymes should be direct tested after design and manufacture of enzymatic coatings.

In the case of physical methods, broad-spectrum antifouling could be performed. Currently, the most successful method is the modification of surface topography, and Sharklet AF has demonstrated to be effective against a variety of fouling organisms. However, the understanding of such mechanisms is still very poor. Although some empirical theories such as attachment point theory and the ERI principle have been proposed, there is a lack of convincing 
explanations focused on the biological process of adhesion. Consequently, it is difficult to apply these results to industrial application. To resolve this, the association between the physical properties of the surface and biochemical process of adhesion needs to be determined.

Although the secretions of organisms such as enzymes and metabolites are biodegradable, it is difficult to anticipate their impact on the marine environment if they are broadly applied on ships. A high concentration of secretions could influence the surrounding marine conditions. In contrast, it is guaranteed that physical methods will not affect the environment. Therefore, physical technologies should be explored more in the future as they are feasible, effective, durable and nontoxic.

This work was supported by the National Natural Science Foundation of China (50675112 and 50721004), and the National Basic Research Program of China (2007CB707702).

1 Yebra D M, Kiil S, Dam J K. Antifouling technology — past, present and future steps towards efficient and environmentally friendly antifouling coatings. Prog Org Coat, 2004, 50: 75-104

2 Champ M. A review of organotin regulatory strategies, pending actions, related costs and benefits. Sci Total Environ, 2000, 258: 21-71

3 Abbott A, Abel P D, Arnold D W, et al. Cost-benefit analysis of the use of TBT: The case for a treatment approach. Sci Total Environ, 2000, 258: 5-19

4 Joseph J C, Ruey J T. Quantifying effects of antifouling paints on microbial biofilm formation. Methods Enzymol, 1999, 310: 637-645

5 Stefan M O. Controlled release of environmentally friendly antifouling agents from marine coatings. Dissertation for Doctoral Degree. Copenhagen: Technical University of Denmark, 2009

6 Maureen E C, Robert L F. The influence of low surface energy materials on bioadhesion - A review. Int Biodeterior Biodegrad, 1994, 34: 333-348

7 Fletcher M, Loeb G I. Influence of substratum characteristics on the attachment of a marine pseudomonad to solid surfaces. Appl Environ Microbiol, 1979, 37: 67-72

8 Walt D R, Smulow J B, Turesky S S, et al. The effect of gravity on initial microbial adhesion. J Colloid Interface Sci, 1985, 107: 334336

9 Per R J, Kent M B, Ann I L. Linking larval supply to recruitment: Flow-mediated control of initial adhesion of barnacle larvae. Ecology, 2004, 85: 2850-2859

10 Chambers L D, Stokes K R, Walsh F C, et al. Modern approaches to marine antifouling coatings. Surf Coat Technol, 2006, 201: 3642-3652

11 Lewin R. Microbial adhesion is a sticky problem. Science, 1984, 224: 375-377

12 Abarzua S, Jakubowski S. Biotechnological investigation for the prevention of biofouling I. Biological and biochemical principles for the prevention of biofouling. Mar Ecol Prog Ser, 1995, 123: 301-312

13 Luciana V R, de Messano, Lucio S, et al. The effect of biofouling on localized corrosion of the stainless steels N08904 and UNS S32760. Int Biodeterior Biodegrad, 2009, 63: 607-614

14 Cooksey K E, Wigglesworth B C. Adhesion of bacteria and diatoms to surfaces in the sea: A review. Aquat Microb Ecol, 1995, 9: 87-96

15 Maki J S, Rittschof D, Schmidt A R, et al. Factors controlling adhesion of bryozoan larvae: A comparison of bacterial films and unfilmed surfaces. Biol Bull, 1989, 177: 295-302

16 Lau S C K, Harder T, Qian P Y. Induction of larval settlement in the serpulid polychaete Hydroides elegans (Haswell): Role of bacterial extracellular polymers. Biofouling, 2003, 19: 197-204

17 Hung O S, Thiyagarajan V, Wu R S S, et al. Effects of ultraviolet radiation on films and subsequent settlement of Hydroides elegans. Mar Ecol Prog Ser, 2005, 304: 155-166

18 Lasa I. Towards the identification of the common features of bacterial biofilm development. Int Microbiol, 2006, 9: 21-28

19 Flemming H C, Griebe T, Schaule G. Antifouling strategies in technical systems-a short review. Water Sci Technol, 1996, 34: 517-524

20 Costerton J W. Overview of microbial biofilms. J Ind Microbiol, 1995, 15: 137-140

21 Stoodley P, Sauer K, Davies D G, et al. Biofilms as complex differentiated communities. Annu Rev Microbiol, 2002, 56: 187-209

22 Waters C M, Bassler B L. Quorum sensing: Cell-to-cell communication in bacteria. Annu Rev Cell Dev Biol, 2005, 21: 319-346

23 Krug P. Defence of benthic invertebrates against surface colonization by larvae: A chemical arms race. Prog Mol Subcell Biol, 2006, 42: $1-53$

24 Jayaraman M, Seetharaman J. Physicochemical analyses of the exopolysaccharides produced by a marine biofouling bacterium, Vibrio alginolyticus. Process Biochem, 2003, 38: 841-847

25 Jakob B K, Rikke L M, Brian S L, et al. Antifouling enzymes and the biochemistry of marine settlement. Biotechnol Adv, 2008, 26: $471-481$

26 Latasa. Biofilm-associated proteins. C R Biologies, 2006, 329 : 849-857

27 Larsen P, Nielsen J L, Dueholm M S, et al. Amyloid adhesins are abundant in natural biofilms. Environ Microbiol, 2007, 9: 3077-3090

28 Yanming X, Keiichi H. Amyloid fibril proteins. Mech Ageing Dev, 2002, 123: 1625-1636

29 Wetzel R, Shivaprasad S, Williams A D. Plasticity of amyloid fibrils. Biochemistry, 2007, 46: 1-10

30 Kiorboe T. Turbulence, phytoplankton cell size, and the structure of pelagic food webs. Adv Mar Biol, 1993, 29: 1-72

31 Finlay J A, Callow M E, Ista L K, et al. Adhesion strength of settled spores of the green alga enteromorpha and the diatom amphora. Integr Comp Biol, 2002, 42: 1116-1122

32 Sitaraman K, Nick W, Christopher K O, et al. Comparison of the fouling release properties of hydrophobic fluorinated and hydrophilic pegylated block copolymer surfaces: Attachment strength of the diatom navicula and the green alga ulva. Biomacromolecules, 2006, 7: 1449-1462

33 Jeffery R S, Sherilyn C F. Three-dimensional modeling of lacustrine diatom habitat areas: Improving paleolimnological interpretation of planktic: Benthic ratios. Limnol Oceanogr, 2004, 49: 1540-1548

34 Gross F, Zeuthen E. The buoyancy of plankton diatoms: A problem of cell physiology. Proc R Soc Lond Ser B, 1948, 135: 382-389

35 Ille C G, Herbert S, Manfred D. Diatom bionanotribology-biological surfaces in relative motion: Their design, friction, adhesion, lubrication and wear. J Nanosci Nanotechno, 2005, 5: 1-9

36 Kellar A, Yiching A L, Tonia S H, et al. Adhesive force of a single gecko foot-hair. Nature, 2000, 405: 681-685

37 Holland R, Dugdale T, Wetherbee R, et al. Adhesion and motility of fouling diatoms on a silicone elastomer. Biofouling, 2004, 20: 323329

38 Edgar L A, Zavortink M. The mechanism of diatom locomotion. II. Identification of actin. Proc R Soc London Ser B, 1983, 218: 345348

39 Nicole C P, Ilan S, Timothy P S, et al. Diatom gliding is the result of an actin-myosin motility system. Cell Motil Cytoskel, 1999, 44: 2333

40 Lind J L, Heimann K, Miller E A, et al. Substratum adhesion and gliding in a diatom are mediated by extracellular proteoglycans. Planta, 1997, 203: 213-221

41 Gordon R, Drum R W. A Capillarity mechanism for diatom gliding locomotion. Proc Natl Acad Sci USA, 1970, 67: 338-344 
42 Edgar L A. Diatom locomotion: A consideration of movement in a highly viscous situation. Eur J Phycol, 1982, 17: 243-251

43 Edgar L A, Pickett H J D. The mechanism of diatom locomotion. i. an ultrastructural study of the motility apparatus. Proc R Soc Lond Ser B, 1983, 218: 331-343

44 Wetherbee R, Lind J L, Burke J, et al. The first kiss: Establishment and control of initial adhesion by raphid diatoms. J Phycol, 1998, 34: 9-15

45 Chiovitti A, Dugdale T M, Wetherbee R. Diatom adhesives: Molecular and mechanical properties. In: Smith A M, Callow J A, eds. Biological Adhesives. Berlin Heidelberg: Springer-Verlag, 2006

46 Bhaskar P V, Narayan B B. Microbial extracellular polymeric substances in marine biogeochemical processes. Curr Sci, 2005, 88: 45-53

47 Rahul A B, PETER G K. Localization of EPS components secreted by freshwater diatoms using differential staining with fluorophoreconjugated lectins and other fluorochromes. Eur J Phycol, 2007, 42: 199-208

48 Yan W, Ya C, Colleen L, et al. Extracellular matrix assembly in diatoms (Bacillariophyceae). IV. Ultrastructure of Achnanthes longipes and Cymbella cistula as revealed by high-pressure freezing/freeze substitution and cryo-field emission scanning electron microscopy. J Phycol, 2000, 36: 367-378

49 Wustman B A, Gretz M R, Hoagland K D. Extracellular matrix assembly in diatoms (Bacillariophyceae) - 1. A model of adhesives based on chemical characterization and localization of polysaccharides from the marine diatom Achnanthes longipes and other diatoms. Plant Physiol, 1997, 113: 1059-1069

50 Rakhee D S K, Narayan B B. Extracellular polymeric substances of the marine fouling diatom amphora rostrata Wm.Sm. Biofouling, 2001, 17: 117-127

51 Michael J H, Simon A C, Paul M, et al. Characterization of the adhesive mucilages secreted by live diatom cells using atomic force microscopy. Protist, 2002, 153: 25-38

52 Michael J H, Paul M, Paul M U, et al. The structure and nanomechanical properties of the adhesive mucilage that mediates diatomsubstratum adhesion and motility. J Phycol, 2003, 39: 1181-1193

53 de Brouwer J F C, Cooksey K E, Wigglesworth C B, et al. Time of flight-secondary ion mass spectrometry on isolated extracellular fractions and intact biofilms of three species of benthic diatoms. J Microbiol Methods, 2006, 65: 562-572

54 Tony M D, Anusuya W, Wetherbee R. Adhesive modular proteins occur in the extracellular mucilage of the motile, pennate diatom phaeodactylum tricornutum. Biophys J, 2006, 90: 58-60

55 John M. A Comparison of the value of various flagellates and diatoms as food for barnacle larvae. ICES J Mar Sci, 1963: 175-187

56 Huang S, Hadfield M G. Composition and density of bacterial biofilms determine larval settlement of the polychaete hydroides elegans. Mar Ecol Prog Ser, 2003, 260: 161-172

57 Patil J S, Anil A C. Influence of diatom exopolymers and biofilms on metamorphosis in the barnacle Balanus amphitrite. Mar Ecol Prog Ser, 2005, 301: 231-245

58 Dobretsov S, Xiong H, Xu Y, et al. Novel antifoulants: Inhibition of larval adhesion by proteases. Mar Biotechnol, 2007, 9: 388-397

59 Nobuhiro F. Biofouling and antifouling. Nat Prod Rep, 2004, 21: 94-104

60 Lagersson N, Høeg J. Settlement behavior and antennary biomechanics in cypris larvae of Balanus amphitrite (Crustacea: Thecostraca: Cirripedia). Mar Biol, 2002, 141: 513-526

61 Kristin Ö, Christian A, James T R, et al. An in vivo study of exocytosis of cement proteins from barnacle Balanus improvisus (D.) cyprid larva. J Exp Biol, 2006, 209: 956-964

62 Callow J A, Crawford S, Higgins M, et al. The application of atomic force microscopy to topographical studies and force measurements on the secreted adhesive of the green alga Enteromorpha. Planta, 2000, 211: 641-647

63 Callow M E, Callow J A, Pickett H J D, et al. Primary adhesion of
Enteromorpha (chlorophyta, Ulvales) propagules: Quantitative settlement studies and video microscopy. J Phycol, 1997, 33: 938-947

64 Rosenhahn A, Finlay J A, Pettit M E, et al. Zeta potential of motile spores of the green alga Ulva linza and the influence of electrostatic interactions on spore settlement and adhesion strength. Biointerphases, 2009, 4: 7-11

65 Ederth T, Nygren P, Pettitt M E, et al. Anomalous settlement behavior of Ulva linza zoospores on cationic oligopeptide surfaces. Biofouling, 2008, 24: 303-312

66 Finlay J A, Callow M E, Schultz M P, et al. Adhesion strength of settled spores of the green alga Enteromorpha. Biofouling, 2002, 18: 251-256

67 Callow J A, Stanley M S, Wetherbee R, et al. Cellular and molecular approaches to understanding primary adhesion in Enteromorpha: An overview. Biofouling, 2000, 16: 141-150

68 Kamino K, Koji I, Tadashi M, et al. Barnacle cement proteins importance of disulfide bonds in their insolubility. J Biol Chem, 2000, 275: 27360-27365

69 Kamino K. Novel barnacle underwater adhesive protein is a charged amino acid-rich protein constituted by a Cys-rich repetitive sequence. Biochem J, 2001, 356: 503-507

70 Admiraal W. Influence of light and temperature on the growth rate of estuarine benthic diatoms in culture. Mar Biol, 1997, 39: 1-9

71 Rascio V J D. Antifouling coatings: Where do we go from here. Corros Rev, 2003, 18: 133-154

72 Peter D S, Schneider R, Staffan K. Chemical defenses of seaweeds against microbial colonization. Biodegradation, 1997, 8: 211-220

73 Callow M E. Ship fouling: Problems and solutions. Chem Ind,1990, 5: 123-127

74 Iwao O. Organotin antifouling paints and their alternatives. Appl Organomet Chem, 2003, 17: 81-105

75 Marson F. Antifouling paints. I. Theoretical approach to leaching of soluble pigments from insoluble paint vehicles. J Appl Chem, 1969, 19: 93-99

76 Rascio V, Giúdice C, Amo B D. High-build soluble matrix antifouling paints tested on raft and ship's bottom. Prog Org Coat, 1990, 18: 389-398

77 Yebra D M, Kiil S, Claus E W, et al. Dissolution rate measurements of sea water soluble pigments for antifouling paints: $\mathrm{ZnO}$. Prog Org Coat, 2006, 56: 327-337

78 Kiil S, Claus E W, Michael S P, et al. Analysis of self-polishing antifouling paints using rotary experiments and mathematical modeling. Ind Eng Chem Res, 2001, 40: 3906-3920

79 Yebra D M, Kiil S, Claus E W, et al. Effects of marine microbial biofilms on the biocide release rate from antifouling paints-modelbased analysis. Prog Org Coat, 2006, 57: 56-66

80 Anna K. Environmental management aspects for TBT antifouling wastes from the shipyards. J Environ Manage, 2009, 90(S): 77-85

81 Wisniewski N, Reichert M. Methods for reducing biosensor membrane biofouling. Colloids Surf B, 2000, 18: 197-219

82 Comber S D W, Franklin G, Gardner M J, et al. Partitioning of marine antifoulants in the marine environment. Sci Total Environ, 2002, 286: 61-71

83 Iwao O. General Aspects of tin-free antifouling paints. Chem Rev, 2003, 103: 3431-3448

84 Voulvoulis N, Scrimshaw M D, Lester J N. Alternative antifouling biocides. Appl Organomet Chem, 1999, 13: 135-143

85 Anita G J B, Sascha B S, Willem H P, et al. Impact of the antifouling agent Irgarol 1051 on marine phytoplankton species. J Sea Res, 2009, 61: 133-139

86 Shtykova L, Fant C, Handa P, et al. Adsorption of antifouling booster biocides on metal oxide nanoparticles: Effect of different metal oxides and solvents. Prog Org Coat, 2009, 64: 20-26

87 Wang J L, Wang F Q, Yu J, et al. A survey analysis of heavy metals bio-accumulation in internal organs of sea shell animals affected by the sustainable pollution of antifouling paints used for ships anchored 
at some domestic maritime spaces. Chinese Sci Bull, 2008, 53: 2471-2475

88 Loschau M, Kratke R. Efficacy and toxicity of self-polishing biocidefree antifouling paints. Environ Pollut, 2005, 138: 260-267

89 Chen M L, Qu Y Y, Yang L, et al. Structures and antifouling properties of low surface energy non-toxic antifouling coatings modified by nano-SiO $\mathrm{S}_{2}$ powder. Sci China Ser B: Chem, 2008, 51: 848-852

90 Brady R F. A fracture mechanical analysis of fouling release from nontoxic antifouling coatings. Prog Org Coat, 2001, 43: 188-192

91 Umemura K, Yamada T, Maeda Y, et al. Regulated growth of diatom cells on self-assembled monolayers. J Nanobiotech, 2007, 5: 2-15

92 Abarzua S, Jakubowski S, Eckert S, et al. Biotechnological investigation for the prevention of marine biofouling II. Blue-green algae as potential producers of biogenic agents for the growth inhibition of microfouling organisms. Bot Mar, 1999, 42: 459-465

93 Xiong H R, Qi S H, Xu Y, et al. Antibiotic and antifouling compound production by the marine-derived fungus Cladosporium sp. F14. J Hydro-environ Res, 2009, 2: 264-270

94 Limna M V P, Raveendran T V, Parameswaran P S. Antifouling activity exhibited by secondary metabolites of the marine sponge, Haliclona exigua (Kirkpatrick). Int Biodeterior Biodegrad, 2009, 63: 67-72

95 Fernando S A, Carlos R. Inhibition of attachment of some fouling diatoms and settlement of Ulva lactuca zoospores by film-forming bacterium and their extracellular products isolated from biofouled substrata in Northern Chile. Electron J Biotechnol, 2008, 11: 1-11

96 Burgess J G, Boyd K G, Armstrong E, et al. The development of a marine natural product-based antifouling paint. Biofouling, 2003, 19(S): 197-205

97 Moss G. Enzyme nomenclature-recommendations of the nomenclature committee of the international union of biochemistry and molecular biology on the nomenclatureand classification of enzymes by the reactions they catalyse. Online edition. International Union of Biochemistry and Molecular Biology (NC-IUBMB). Tipton K F, Boyce $\mathrm{S}$, eds. Department of Chemistry, Queen Mary University of London, Mile End Road, London, E1 4NS, UK. http://www.chem. qmul.ac.uk/iubmb/enzyme/index.html. 2006. Accessed 01-27-2008

98 Pettitt M E, Henry S L, Callow M E, et al. Activity of commercial enzymes on settlement and adhesion of cypris larvae of the barnacle balanus amphitrite, spores of the green alga Ulva linza, and the diatom Navicula perminuta. Biofouling, 2004, 20: 299-311

99 Charlotte J, Falholt P, Gram L. Enzymatic removal and disinfection of bacterial biofilms. Appl Environ Microbiol, 1997, 63: 3724-3728

100 Asuri P, Sandeep S K, Ravi S K, et al. Polymer-nanotube-enzyme composites as active antifouling films. Small, 2007, 3: 50-53

101 Kim Y D, Jonathan S D, Douglas S C. Siloxane-based biocatalytic films and paints for use as reactive coatings. Biotechnol Bioeng, 2001, 72: $475-482$

102 Novick S J, Jonathan S D. Protein-containing hydrophobic coatings and films. Biomaterials, 2002, 23: 441-448

103 Leroy C, Delbarre C, Ghillebaert F, et al. Effects of commercial enzymes on the adhesion of a marine biofilm-forming bacterium. Biofouling, 2008, 24: 11-22

104 Luckarift H R, Matthew B D, Kenneth H S, et al. Room-tempera- ture synthesis of antibacterial bionanocomposites of lysozyme with amorphous silica or titania. Small, 2006, 2: 640-643

105 Nick A, Phang I Y, Conlan S L, et al. The effects of a serine protease, Alcalase, on the adhesives of barnacle cyprids (Balanus amphitrite). Biofouling, 2008, 24: 97-107

106 Chiovitti A, Higgins M J, Harper R E, et al. The complex polysaccharides of the raphid diatom Pinnularia viridis (Bacillariophyceae). J Phycol, 2003, 39: 543-54

107 Joao B X, Cristian P, Suriani A R, et al. Biofilm-control strategies based on enzymic disruption of the extracellular polymeric substance matrix-A modelling study. Microbiology, 2005, 151: 3817-3832

108 Boyd A, Chakrabarty A M. Role of alginate lyase in cell detachment of Pseudomonas aeruginosa. Appl Environ Microbiol, 1994, 60:
2355-2359

109 Imlay J A. Pathways of oxidative damage. Annu Rev Microbiol, 2003, 57: 395-418

110 Callow J A, Callow M E. Biofilms. Prog Mol Subcell Biol, 2006, 42: 141-169

111 Huang Y L, Dobretsov S, Jang S K, et al. Presence of acylhomoserine lactone in subtidal biofilm and the implication in larval behavioral response in the polychaete hydroides elegans. Microb Ecol, 2008, 54: 384-392

112 Olsen S M, Pedersen L T, Laursen M H, et al. Enzyme-based antifouling coatings: A review. Biofouling, 2007, 23: 369-383

113 Chiang W C, Chyou S D, Huang R, et al. Control of marine biofouling by conductive coatings. Corros Prevent Control, 2000, 47: $121-128$

114 Tadashi M, Tae K L. Electrochemical prevention of biofouling. Electrochemistry, 2000, 68: 847-852

115 Liang C H, Huang N B. Research on electrochemical behavior of titanium-supported anodic coating in electrolytic anti-fouling of brine. Mater Chem Phys, 2008, 111: 244-248

116 Sanford E B, Rittscho D. An investigation of low frequency sound waves as a means of inhibiting barnacle settlement. J Exp Mar Biol Ecol, 1984, 79: 149-154

117 Miloud R, Mireille L. Application of mechanical waves induced by piezofilms to marine fouling protection of oceanographic sensors. Smart Mater Struct, 1995, 4: 195-201

118 Finlay J A, Fletcher B R, Callow M E, et al. Effect of background colour on growth and adhesion strength of Ulva sporelings. Biofouling, 24: 219-225

119 Swain G, Herpe S, Ralson E, et al. Short-term testing of antifouling surfaces: The importance of colour. Biofouling, 2006, 22: 425-429

120 Bowen J, Pettitt M E, Kendall K, et al. The influence of surface lubricity on the adhesion of Navicula perminuta and Ulva linza to alkanethiolself-assembled monolayers. J R Soc Interface, 2007, 4: 473-477

121 Ista L, Callow M, Finlay J, et al. Effect of substratum surface chemistry and surface energy on adhesion of marine bacteria and algal spores. Appl Environ Microbiol, 2004, 70: 4151-4157

122 Mark P, Paul T, Sara S, et al. Effects of ultrafiltration membrane surface properties on Pseudomonas aeruginosa biofilm initiation for the purpose of reducing biofouling. J Membrane Sci, 2001, 194: 15-32

123 Callow M E, Callow J A, Ista L K, et al. The use of self-assembled monolayers (SAMs) of different wettability to study surface selection and primary adhesion processes of zoospores of the green alga Enteromorpha. Appl Environ Microbiol, 2000, 66: 3249-3254

124 Statz A, Finlay J, Dalsin J, et al. Algal antifouling and fouling-release properties of metal surfaces coated with a polymer inspired by marine mussels. Biofouling, 2006, 22: 391-399

125 Schilp S, Kueller A, Rosenhahn A, et al. Settlement and adhesion of algal cells to hexa(ethylene glycol)-containing self-assembled monolayers with systematically changed wetting properties. Biointerphases, 2007, 2: 143-150

126 Dineshrama R, Subasrib R, Somarajub K R C, et al. Biofouling studies on nanoparticle-based metal oxide coatings on glass coupons exposed to marine environment. Colloids Surf B, 2009, 74: 75-83

127 Finlay J A, Krishnan S, Callow M E, et al. Settlement of Ulva zoospores on patterned fluorinated and PEG-lated monolayer surfaces. Langmuir, 2008, 24: 503-510

128 Grozea C M, Gunari N, Finlay J A, et al. Water-stable diblock polystyrene-block-poly(2-vinyl pyridine) and diblock polystyrene-blockpoly(methyl methacrylate) cylindrical patterned surfaces inhibit settlement of zoospores of the green alga ulva. Biomacromolecules, 2009, 10: 1004-1012

129 Scardino A J, Harvey E R, de Nys R. Testing adhesion point theory: diatom adhesion on microtextured polyimide biomimics. Biofouling, 2006, 22: 55-60

130 Scardino A J, Guenther J, de Nys R. Attachment point theory revisited: The fouling response to a microtextured matrix. Biofouling, 2008, 
24: 45-53

131 Berntsson K M, Andreasson H, Jonsson P R, et al. Reduction of barnacle recruitment on micro-textured surfaces: Analysis of effective topographic characteristics and evaluation of skin friction. Biofouling, 2000, 16: 245-261

132 Schumacher J F, Carmen M L, Estes T G, et al. Engineered antifouling microtopographies-Effect of feature size, geometry, and roughness on settlement of zoospores of the green alga Ulva. Biofouling, 2007, 23: 55-62

133 Carmen M L, Estes T G, Feinberg A W, et al. Engineered antifouling microtopographies-Correlating wettability with cell attachment. Biofouling, 2006, 22: 11-21

134 Chung K K, Schumacher J F, Sampson E M, et al. Impact of engineered surface microtopography on biofilm formation of Staphylococcus aureus. Biointerphases, 2007, 2: 89-94

135 Knoell T, Safarik J, Cormack T, et al. Biofouling potentials of microporous polysulfone membranes containing a sulfonated polyether-ethersulfone/polyethersulfone block copolymer: Correlation of membrane surface properties with bacterial attachment. J Membr Sci, 1999, 157: 117-138

136 Busscher H J, van de Belt-Gritter B, van der Mei H C. Implications of microbial adhesion to hydrocarbons for evaluating cell surface hydrophobicity 1. Zeta potentials of hydrocarbon droplets. Colloids Surf B, 1995, 5: 111-116

137 Wilson W W, Wade M M, Holman S C, et al. Status of methods for assessing bacterial cell surface charge properties based on zeta potential measurements. J Microbiol Methods, 2001, 43: 153-164

138 Kamlesh A S, Ashwin K B, Ali B, et al. Zeta potential of selected bacteria in drinking water when dead, starved, or exposed to minimal and rich culture media. Curr Microbiol, 2008, 56: 93-97

139 Rita K H, Andy B, Simon A P, et al. Characterisation of algogenic organic matter extracted from cyanobacteria, green algae and diatoms. Water Res, 2008, 42: 3435-3445

140 Dittrich M, Sibler S. Cell surface groups of two picocyanobacteria strains studied by zeta potential investigations, potentiometric titration, and infrared spectroscopy. J Colloid Interface Sci, 2005, 286: 487-495

141 Maria O P, Maria J V, Vitorino M B, et al. Retention of bacteria by cellulose fibers as a means of reducing biofouling in paper pulp production process. Biofouling, 1998, 13: 1-18

142 Herrwerth S, Eck W, Reinhardt S, et al. Factors that determine the protein resistance of oligoether self-assembled monolayers-Internal hydrophilicity, terminal hydrophilicity, and lateral packing density. J Am Chem Soc, 2003, 125: 9359-9366

143 Soeren S, Alexander K, Axel R, et al. Settlement and adhesion of algal cells to hexa (ethylene glycol)-containing self-assembled monolayers with systematically changed wetting properties. Biointerphases, 2007, 2: 143-150

144 Jurgen K H, Richard L C W, Michael G. Hydroxide ion adsorption on self-assembled monolayers. J Am Chem Soc, 2003, 125: 8384-8389

145 Jansen B, Kohnen W. Prevention of biofilm formation by polymer modification. J Ind Microbiol, 1995, 15: 391-396

146 Gross M, Carmton S E, Gotz F, et al. Key role of teichoic acid net charge in staphylococcus aureus colonization of artificial surfaces. Infec Immunity, 2001, 69: 3423-3426

147 Schumacher J F, Long C J, Callow M E, et al. Engineered nanoforce gradients for inhibition of settlement (attachment) of swimming algal spores. Langmuir, 2008, 24: 4931-4937

Open Access This article is distributed under the terms of the Creative Commons Attribution License which permits any use, distribution, and reproduction in any medium, provided the original author(s) and source are credited. 